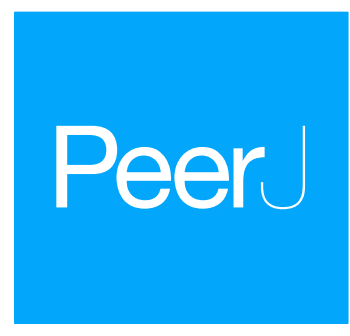

Submitted 21 May 2018

Accepted 20 September 2018

Published 23 October 2018

Corresponding author

Ella T. Sieradzki,

ellasiera@berkeley.edu

Academic editor

Michael Rappe

Additional Information and Declarations can be found on page 19

DOI 10.7717/peerj.5798

Copyright

2018 Sieradzki et al.

Distributed under

Creative Commons CC-BY 4.0

OPEN ACCESS

\section{Proteorhodopsins dominate the expression of phototrophic mechanisms in seasonal and dynamic marine picoplankton communities}

\author{
Ella T. Sieradzki, Jed A. Fuhrman, Sara Rivero-Calle and \\ Laura Gómez-Consarnau \\ Department of Biological Sciences, University of Southern California, Los Angeles, CA, \\ United States of America
}

\section{ABSTRACT}

The most abundant and ubiquitous microbes in the surface ocean use light as an energy source, capturing it via complex chlorophyll-based photosystems or simple retinalbased rhodopsins. Studies in various ocean regimes compared the abundance of these mechanisms, but few investigated their expression. Here we present the first full seasonal study of abundance and expression of light-harvesting mechanisms (proteorhodopsin, PR; aerobic anoxygenic photosynthesis, AAnP; and oxygenic photosynthesis, PSI) from deep-sequenced metagenomes and metatranscriptomes of marine picoplankton $(<1 \mu \mathrm{m})$ at three coastal stations of the San Pedro Channel in the Pacific Ocean. We show that, regardless of season or sampling location, the most common phototrophic mechanism in metagenomes of this dynamic region was PR (present in 65-104\% of the genomes as estimated by single-copy recA), followed by PSI (5-104\%) and AAnP (5-32\%). Furthermore, the normalized expression (RNA to DNA ratio) of PR genes was higher than that of oxygenic photosynthesis (average \pm standard deviation $26.2 \pm 8.4$ vs. $11 \pm 9.7$ ), and the expression of the AAnP marker gene was significantly lower than both mechanisms $(0.013 \pm 0.02)$. We demonstrate that PR expression was dominated by the SAR11-cluster year-round, followed by other Alphaproteobacteria, unknownenvironmental clusters and Gammaproteobacteria. This highly dynamic system further allowed us to identify a trend for PR spectral tuning, in which blue-absorbing PR genes dominate in areas with low chlorophyll- $a$ concentrations $\left(<0.25 \mu \mathrm{gL}^{-1}\right)$. This suggests that PR phototrophy is not an accessory function but instead a central mechanism that can regulate photoheterotrophic population dynamics.

Subjects Biodiversity, Bioinformatics, Ecology, Microbiology, Biological Oceanography Keywords Phototrophy, Proteorhodopsin, Metatranscriptome, Metagenome, Spectral tuning, Marine, Picoplankton, Expression

\section{INTRODUCTION}

Sunlight is the most readily available source of energy in the photic zone of the ocean. Light utilization in marine microorganisms is divided between complex, high-yield photosystems (oxygenic and anoxygenic photosynthesis) and simple, low-yield rhodopsins (Finkel, Béjà \& Belkin, 2013). Light-harvesting mechanisms span the entire visible light spectrum, with bacteriochlorophyll-a and chlorophyll- $a$ (Chl- $a$ ) utilizing its extremes, and various types 
of rhodopsins absorbing intermediate frequencies (Fuhrman, Schwalbach \& Stingl, 2008). Since the discovery of proteorhodopsin proteins (Béjà et al., 2000; Béjà et al., 2001) they were found to be globally abundant across various oceanic regimes (Rusch et al., 2007; Boeuf et al., 2016; Brindefalk et al., 2016; Dubinsky et al., 2017). Among the known microbial rhodopsins, type-1 proton pumping proteorhodopsins (PR) are the most abundant and widespread in marine systems (Pinhassi et al., 2016); herein we will refer to all microbial rhodopsins as PR for simplicity. Genomic studies showed that the gene coding for PR is present in some of the most abundant bacteria in the ocean, e.g., SAR11 and SAR86 (Béjà et al., 2000; Sabehi et al., 2004; Giovannoni et al., 2005). PR-coding genes have also been found in some microbial eukaryotes such as fungi and photosynthetic protists, as well as in archaea and even in viruses as an auxiliary metabolic gene (Philosof \& Béjà, 2013; reviewed by Pinhassi et al., 2016). PRs are the simplest light-harvesting mechanisms known to date, containing only one membrane protein and a retinal chromophore (Béjà et al., 2000). Light-driven proton pump PRs can increase the membrane potential of the cell, ultimately supporting a variety of processes such as ATP synthesis (Béjà et al., 2000; Walter et al., 2007; Steindler et al., 2011), substrate uptake (Steindler et al., 2011; Gómez-Pereira et al., 2013; Gómez-Consarnau et al., 2016), survival during starvation (Gómez-Consarnau et al., 2010; Steindler et al., 2011) and/or salinity stress response (Feng et al., 2013). Taken together, their structural simplicity and the range of functions they can support seem to have promoted the expansion of PRs in the sunlit ocean. However, estimates of the relative abundance of PR genes using metagenomics (Finkel, Béjà \& Belkin, 2013; Brindefalk et al., 2016; Dubinsky et al., 2017) or metatranscriptomics (Shi et al., 2011; Kopf et al., 2015) have only been examined recently. In contrast to qPCR methods, next generation sequencing techniques can provide more reliable estimates without introducing $\mathrm{QPCR}$ and cloning biases that would miss certain PR gene types (Nguyen et al., 2015; Boeuf et al., 2016).

PR genes are highly expressed in the photic zone (Frias-Lopez et al., 2008; Poretsky et al., 2009; Satinsky et al., 2014). While generally transcription is not always an indicator of protein activity, one study shows good correlation between PR transcription and synthesis in a diatom (Marchetti et al., 2015) and another shows diel oscillations in PR transcription that peak before dawn, implying a preparation for light harvesting during the day (Ottesen et al., 2014). Bacteria in the genus Dokdonia upregulate the expression of PR genes in the light only in oligotrophic seawater conditions (Riedel et al., 2010; Gómez-Consarnau et al., 2016). Combined, these results may indicate that transcription levels are a good proxy for PR synthesis at least in some microbes. However, a cultured SAR11 strain has little regulation at the protein expression level and its PR genes appear to be constitutively expressed in light and dark (Giovannoni et al., 2005). All in all, there is limited information on the expression of PR compared to other light-harvesting mechanisms. In contrast with the established global distribution and abundance of PR taxonomic clusters, very few studies have compared their expression in environmental samples (Shi et al., 2011; Kopf et al., 2015; Boeuf et al., 2016; Brindefalk et al., 2016; Vader et al., 2018). Additionally, the vast majority of studies have been based on single time-points, with the exception of Sabehi et al. (2007), which compared winter and summer expression at two sites (Mediterranean and Sargasso Sea) and Nguyen et al. (2015), which compared early- and late-winter expression 
in the Arctic. Thus, information on temporal expression patterns of different PR clades remains scarce.

PR has two main variants that differ in their light absorption spectrum (Béjà et al., 2001; Man et al., 2003). This spectral tuning is determined by a single residue at the frequency-tuning site (FTS) (Man et al., 2003). It has been proposed that spectral tuning is related to the spectral quality and quantity of light in the water, i.e., water color. Consistent with this pattern, green-tuned PR are generally common in coastal waters, whereas the blue-tuned counterparts are typical of open-ocean or deeper water (Fuhrman, Schwalbach \& Stingl, 2008) and references therein; (Pinhassi et al., 2016). For instance, while more than $70 \%$ of the PR sequences retrieved from the ultraoligotrophic Eastern Mediterranean were classified as blue-absorbing (Dubinsky et al., 2017), less than 10\% belonged to this group in the eutrophic Baltic sea (Brindefalk et al., 2016). These data suggest that seasonal and more contrasting spatial variability could potentially determine the PR spectral tuning trends, namely that there is a direct correlation between spectral tuning and the trophic state of the water. However, no study to date has evaluated: (1) whether this distribution pattern actually applies to more dynamic environments with contrasting trophic conditions associated to seasonal and spatial gradients, or (2) whether the specific underwater light field could be an important ecological driver for photoheterotrophic populations in nutrient dynamic regions.

Here we present the first seasonal study of PR in metagenomes and metatranscriptomes of surface water microbial communities at three contrasting locations in the San Pedro Channel (Fig. 1). The transect spanned $37 \mathrm{~km}$ between the highly polluted Port of Los Angeles and the mildly impacted Santa Catalina Island, with the largely oligotrophic San Pedro Ocean Time-series (SPOT) halfway between them. The contrasting nature of those stations was observed in their inorganic nutrient concentration, chlorophyll levels, bacterial and viral counts and heterotrophic production (Table S1). We further compared PR abundance and distribution to the other two main phototrophic metabolisms in surface waters: oxygenic photosynthesis (PSI) and aerobic anoxygenic phototrophy (AAnP). Our data show that PR is the dominant phototrophic metabolism in microbial metagenomes and metatranscriptomes of this dynamic environment year-round.

\section{MATERIAL AND METHODS}

\section{Sample collection}

Ten liters of surface seawater (mixed layer depth 5-40 m) were collected from the Port of Los Angeles (POLA, $33^{\circ} 42.75^{\prime} \mathrm{N} 118^{\circ} 15.55^{\prime} \mathrm{W}$ ), the San Pedro Ocean Time-series (SPOT, $33^{\circ} 33.00^{\prime} \mathrm{N} 118^{\circ} 24.01^{\prime} \mathrm{W}$ ) and Two Harbors, Santa Catalina Island (CAT, $33^{\circ} 27.18^{\prime} \mathrm{N} 118^{\circ} 28.51^{\prime} \mathrm{W}$ ) in four seasons: July 2012, October 2012, January 2013 and April 2013. All samples were collected in the morning between 7 am and $12 \mathrm{pm}$. For nucleic acids extraction, seawater was prefiltered through a $1 \mu \mathrm{m}$ glass fiber syringe filter (Pall, Acrodisc $25 \mathrm{~mm}$ ) followed by a $0.22 \mu \mathrm{m}$ Sterivex polyethersulfone filter (PES, Millipore, SVGPL10RC) with a maximum filtration time of $20 \mathrm{~min}$. Due to high sequencing costs, no replicate samples were taken for metagenome and metatranscriptome analysis. $1.5 \mathrm{ml}$ 


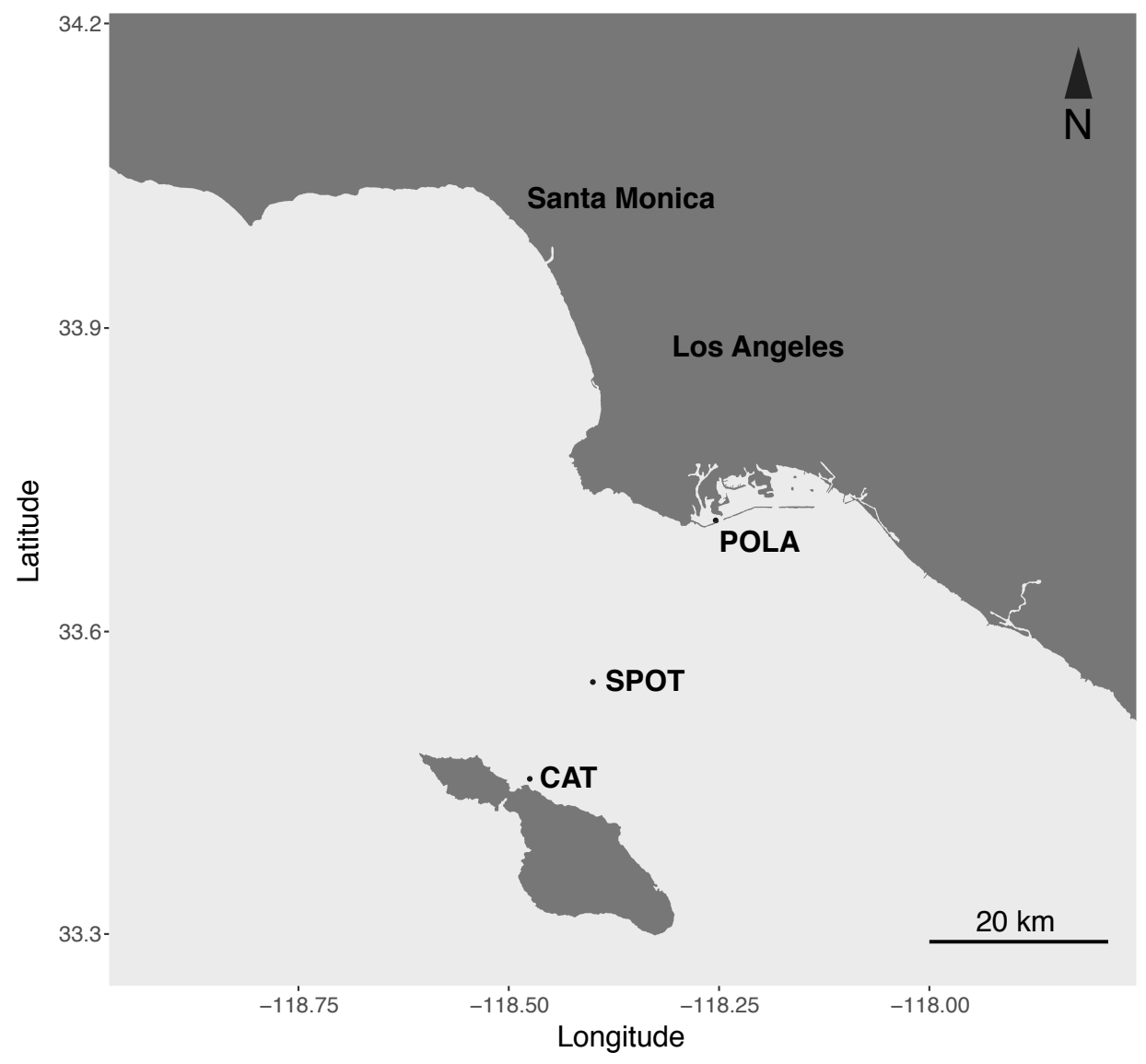

Figure 1 Map of the sampling sites. Port of Los Angeles (POLA, $33^{\circ} 42.75^{\prime} \mathrm{N}, 118^{\circ} 15.55^{\prime} \mathrm{W}$ ), San Pedro Ocean Time-series (SPOT, $33^{\circ} 33^{\prime} \mathrm{N}, 118^{\circ} 24^{\prime} \mathrm{W}$ ) and Catalina Island (CAT, $33^{\circ} 27.17 \mathrm{~N}, 118^{\circ} 28.51^{\prime} \mathrm{W}$ ). Full-size DOI: $10.7717 /$ peerj.5798/fig-1

RNAlater was added into the Sterivex filters and they were sealed, flash frozen in liquid nitrogen and stored at $-80^{\circ} \mathrm{C}$ until extraction.

\section{Chemical and biological parameters}

Whole seawater for nutrients measurement were collected in triplicates in $50 \mathrm{~mL}$ conical tubes and kept in $-20^{\circ} \mathrm{C}$ until flow-injection analysis at the Marine Sciences Institute Analytical Lab at University of California, Santa Barbara (http://www.msi.ucsb.edu/ services/analytical-lab). Bacteria and viruses per ml seawater were counted on duplicate slides using SYBR green epifluorescence microscopy (Noble \& Fuhrman, 1998; Patel et al., 2007). For chlorophyll- $a$ measurement, triplicates of 50-500 mL of whole seawater were filtered onto $25 \mathrm{~mm} \mathrm{GF} / \mathrm{F}$ filters and stored at $-20{ }^{\circ} \mathrm{C}$ until analysis within the week. Filters were extracted with $4 \mathrm{~mL}$ of $100 \%$ acetone at $-20{ }^{\circ} \mathrm{C}$ overnight in the dark, and processed on a calibrated Trilogy Laboratory Fluorometer (Turner Designs, San Jose, CA, USA) using the non-acidification method (Welschmeyer \& Naughton, 1994). See Table S1 for all measured values. 


\section{Nucleic acids extraction and Library preparation}

After thawing the Sterivex filters, RNAlater was removed using a syringe in order to improve DNA yield. Cells on the filters were lysed by bead-beating for two cycles of $10 \mathrm{~min}$ each with $0.1 \mathrm{~mm}$ glass beads in $1.5 \mathrm{ml}$ Sodium chloride-Tris-EDTA (STE) buffer injected into the Sterivex. DNA and RNA were then extracted from the flow-through using the AllPrep kit (Qiagen) that yields RNA and DNA from the same sample simultaneously. This process included treating the RNA columns with DNAse. The mean extraction yield was $2 \mu \mathrm{g}$ DNA and $9 \mu \mathrm{g}$ RNA per $10 \mathrm{~L}$ water. After extraction and quality assessment with Qubit HS (Thermo-Fisher Scientific, Waltham, MA, USA) and Bioanalyzer 2100 (Agilent, Santa Clara, CA, USA) nucleic acids were stored at $-80{ }^{\circ} \mathrm{C}$ until further processing. As a sanity check, we used the reciprocal Qubit kits to quantify RNA in the eluted DNA and DNA in the eluted RNA and both were below detection in all samples. RNA samples were spiked with an internal standard for quantitative assessment of the sequencing process (ERCC RNA Spike-In Mix, Thermo Fisher 4456740; Thermo Fisher Scientific, Waltham, MA, USA) and converted to cDNA using the SuperScript III reverse transcriptase kit (Thermo Fisher Scientific, Waltham, MA, USA). Libraries were prepared using Ovation Ultralow library system V2 (0344; Nugen, Redwood City, CA, USA) from 200 ng DNA or cDNA mechanically sheared by Covaris M2. To ascertain that there were no contaminants in any reagents used in the extraction, library prep and sequencing processes, negative control libraries were generated by running Tris-EDTA buffer through the AllPrep kit and using the eluent as input for the Ovation ultralow library kit. All libraries were then sequenced on Illumina HiSeq $2 \times 125$ bp or $2 \times 150$ bp for metagenomes and $2 \times 250$ bp for metatranscriptomes.

\section{S/18S-rRNA amplification and sequencing}

Hypervariable regions V4-V5 were amplified from DNA and cDNA of all samples following the protocol described in Parada, Needham \& Fuhrman (2016) using dual barcoded primers. All PCR products were bead-cleaned with Ampure beads at a $1 \times$ beads to sample ratio, diluted to $1 \mathrm{ng} / \mu \mathrm{l}$ and pooled. The pool was bead cleaned again at a $0.8 \times$ beads to pool ratio. Insert size was verified on an Agilent 2100 Bioanayzer and the pool was sequenced on Illumina MiSeq 300 bp paired-end at the UC Davis genome core.

The resulting reads were quality-trimmed using Trimmomatic version 0.33 (Bolger, Lohse \& Usadel, 2014) with parameters set to Leading:20 Trailing:20 Slidingwindow:15:25. The reads were then merged with Usearch 7 (Edgar, 2010) and analyzed using Mothur (Kozich et al., 2013) following the Miseq SOP (https://www.mothur.org/wiki/MiSeq_SOP) with an OTU preclustering cutoff of 2 mismatches and clustering at $99 \%$ sequence identity.

Reads that failed to merge, and were therefore more likely to represent 18S-rRNA, were first concatenated with an additional $\mathrm{N}$ base between the forward and reversecomplemented reverse read as described in (Needham \& Fuhrman, 2016), and then clustered with usearch 6.1 (Edgar, 2010) at 97\% identity via the Qiime 1 platform (Caporaso et al., 2010). Taxonomy was assigned using SILVA release 132 (Yilmaz et al., 2013). These reads were used only to estimate the relative abundance of diatoms in all samples. 


\section{Metagenomes and metatranscriptomes sequence quality trimming}

Quality trimming was performed using Trimmomatic 0.33 (Bolger, Lohse \& Usadel, 2014) with parameters set to Leading:20 Trailing:20 Slidingwindow:15:25. Internal standard reads were removed from the metatranscriptomes informatically after confirming that their relative abundance out of all reads matched the relative abundance of the original spike-in. Metatranscriptomic reads were merged with PEAR (Zhang et al., 2013). Metagenomic reads could not be merged due to insert length and only the forward read was used for short read placement (see below). Sequencing depth after quality control is detailed in Table S2.

\section{Marker genes selection}

The marker genes used for each of the light-harvesting mechanisms has previously been established (Finkel, Béjà \& Belkin, 2013). Those are single-copy genes in most cases and can be found in all organisms that use the particular mechanisms. These genes can also be correlated to phylogeny, albeit not at very a high resolution and with the caveat that they (mainly PR) can be laterally transferred. Those marker genes can be used to track global distribution as well as expression. The PR gene codes for the transmembrane protein of proteorhodopsin, which anchors the retinal light-harvesting pigment. $p s a A$ codes for apoprotein a1 which binds P700, the main electron donor of photosystem-I, and pufM codes for chain $\mathrm{M}$ in the reaction center of the anoxygenic bacteriochlorophyll (Finkel, Béjà \& Belkin, 2013).

\section{Assembly}

Contigs were assembled within each metagenome/metatranscriptome separately with Megahit v1.0.4 (Li et al., 2015) and clustered with cd-hit (Fu et al., 2012) at 99\% sequence identity to reduce complexity. Contigs longer than 2,000 kbp from all samples were then co-assembled with Minimus2 (Sommer et al., 2007) and shorter contigs were co-assembled with Newbler (Margulies et al., 2005). Both co-assemblies required a minimum overlap of $200 \mathrm{bp}$ and a minimum sequence identity $99 \%$ and all resulting contigs were clustered again with cd-hit at $99 \%$ sequence identity. The overlap assembly was performed under the assumption that if longer contigs could have formed using kmer-based assemblers they would have done so within each sample.

\section{Marker gene extraction from assemblies}

Open reading frames (ORFs) were identified in the assembled contigs using prodigal version 2.6.2 (Hyatt et al., 2010). The resulting translated ORFs were then scanned for PR, PsaA, PufM, PufL and RecA proteins via Anvi'o (Eren et al., 2015), and ORF sequences long enough to not affect the curated alignment ( $>200$ aa, see below) were added to the protein dataset used for phylogenetic placement (see below). Assembled PsaA ORFs were all placed within the eukaryotic cluster possibly due to higher microdiversity of cyanobacteria. High microdiversity can cause assemblies to break (Martinez-Hernandez et al., 2017), explaining the lack of assembled cyanobacterial PsaA ORFs despite the fact that cyanobacterial PsaA was much more abundant in the small size fraction compared to picoeukaryotic PsaA (Fig. S1). Assembled PR ORFs represented multiple clusters and contributed significantly to 
recruitment (Table S3), and no assembled PufM ORFs matched our criteria. The gene recA was used to calculate the relative abundance of PR, PsaA and PufM in genomes (Brindefalk et al., 2016). Even though not all bacteria have recA, this gene has been previously assessed as nearly ubiquitous (Rocha, Santos \& Pacheco, 2015) and is known to be present in all the taxonomic groups relevant in this surface marine environment. $r e c A$ abundance was also previously shown to be very similar to other housekeeping genes ( $g y r B, r p o B$ and $t u f$ ) (Dubinsky et al., 2017).

\section{Phylogenetic trees}

Curated protein subsets limited to aquatic bacteria, archaea, viruses and picoeukaryotes of PsaA, PufM and PufL were downloaded from Pfam (Finn et al., 2016) and RefSeq. These sets were supplemented by the respective assembled ORFs. Two sets of sequences were aligned using mafft (Katoh \& Standley, 2013) (globalpair, gap open penalty 1.5, gap extension penalty 0.5 and scoring matrix BLOSUM30) and alignment trimming (Gblocks $\mathrm{b} 3=50, \mathrm{~b} 4=5, \mathrm{~b} 5=\mathrm{h},($ Castresana, 2000): one set of $p s a A$ only and the other of $p s b A, p u f M$ and $p u f L$ which are homologous. Each alignment was then used to build a Hidden Markov Model (HMM) using HMMER 3.0 (Johnson, Eddy \& Portugaly, 2010) and a maximum likelihood tree with RAxML v8.2.5 (Stamatakis, 2014) using WAG substitution matrix and Gamma model (Ignacio-Espinoza \& Sullivan, 2012). The trees are provided in Figs. S2 and $\mathrm{S} 3$.

A curated alignment and a phylogenetic tree of PR proteins was graciously provided by the MicRhoDE project (Boeuf et al., 2015) and included type-I proteorhodopsins as well as other rhodopsin clusters. The alignment was used to build an HMM of the PR amino acid sequence via hmmbuild. The assembled ORFs were first placed into the MicRhoDE tree (see Table S3 for placements) and the resulting tree was used for placement of short reads.

\section{Short reads placement}

Most studies use either best blast hit or reciprocal blast to recruit reads to PR, whereas we used a combination of blastx, HMM (Hidden Markov Models) and placement of short translated reads into phylogenetic protein trees. This method almost always yielded many more reads than reciprocal blast, which is intentionally a very conservative estimate (Fig. S4).

All reads from the metagenomes and metatranscriptomes were searched against the curated protein datasets using blastx (Camacho et al., 2009) requiring an $e$-value of $10^{-5}$. Reads that hit those genes were translated and filtered again using the HMMs with hmmsearch. Hits with an $e$-value lower than $10^{-5}$ were aligned to the dataset using hmmalign. The aligned reads were placed into the phylogenetic trees with pplacer 1.1 run with default settings (Matsen, Kodner \& Armbrust, 2010). Only reads that mapped to leaves (rather than internal nodes) were further analyzed.

The same process with the exception of placement into a phylogenetic tree was performed for RecA and used for normalization of the functional genes.

Gene abundances were determined by the formula used by Dubinsky et al. (2017) (funcAbun/funcLen)/(RecAAbun/RecALen) 
where func is any functional gene ( $p s a A, P R$ or $p u f M$ ), funcAbun is the relative abundance of reads placed into leaves in the phylogenetic tree of this functional gene per sample, funcLen is the length of the HMM built for the functional gene, RecAAbun is the relative abundance of reads mapped to RecA per sample by HMM and RecALen is the length of the RecA HMM.

\section{Reciprocal blast}

For comparability to previous papers, reads mapping to all genes were also extracted from the metagenomes and metatranscriptomes using reciprocal blast. First, we built a blast database from every metagenome and metatranscriptome. Then we used the curated sequences described above as a query to search these databases using tblastn (Camacho et al., 2009). The reads that resulted from this search were then searched against the NCBI non-redundant database (nr) using blastx (Camacho et al., 2009), and only reads that hit the desired genes were retained. General trends between genes were similar using this method compared to HMMs but the number of recruited reads was almost always significantly lower for the functional genes (Fig. S3).

\section{Spectral tuning of PR}

Reads that mapped to the frequency tuning site (FTS) in the protein alignment (using HMMalign) were analyzed to determine tuning relative abundance of blue (glutamine) or green (leucine or methionine). While other residues were observed, they were extremely rare and therefore not included in the analysis.

\section{Underwater light field}

Unfortunately, no in situ irradiance data could be collected at the time of sampling, therefore we resorted to well-established satellite remote sensing data. Ocean color satellites can return information on the underwater light quality and quantity through the remote

sensing reflectance (Rrs, unit: $\mathrm{sr}^{-1}$ ) parameter, which is the relationship of upwelling water leaving radiance ( $\mathrm{Lw}$, units: $\mathrm{W} \mathrm{m}^{-2} \mathrm{sr}^{-1} \mathrm{~nm}^{-1}$ ) to downwelling irradiance (Ed, units: $\mathrm{W}$ $\mathrm{m}^{-2} \mathrm{~nm}^{-1}$ ) integrated over the first optical depth. Lw and Ed are the typical parameters that would have been measured in situ. Rrs is defined as:

Rrs $=$ Lw/Ed

Since Rrs is wavelength-dependent, the shape and height of the spectrum can tell us about the availability and quality of the underwater light field.

\section{Satellite data acquisition and analysis}

MODIS level 3 mapped daily $4 \mathrm{~km}$ resolution satellite products of remote sensing reflectance (Rrs) were downloaded from the NASA ocean color distribution website (https://oceancolor.gsfc.nasa.gov) in October 2017. Satellite products for this study were extracted for each location and date, spanning six days before and one day after sampling, thus exploring the short temporal variability as well. We averaged our satellite estimates within a 0.15 degree radius from each sampling location. With the exception of October, there was no satellite data on the exact day of sampling, therefore we used data from the next day. 


\section{Statistics}

Shannon index of evenness was calculated using the R package RAM. and one-sided paired $t$-test between gene abundance evenness and expression evenness was run using $\mathrm{R}$ basic package with $\mathrm{mu}=0$.

Spearman correlations were calculated using the corr.test function within the $R$ package psych. This function can calculate Spearman correlations with $p$-value correction for multiple tests (we used option "fdr" for the correction).

\section{Map of sampling sites}

The map was plotted using R package ggmap (Kahle \& Wickham, 2013).

\section{RESULTS}

\section{Abundance and expression of light-harvesting mechanisms}

We estimated the fraction of microbial cells that contain each of the light-harvesting mechanisms by normalizing the relative abundance of genes coding for microbial rhodopsins $(P R)$, photosystem-I ( $p s a A)$ and aerobic anoxygenic photosynthesis ( $p u f M$ ) to the relative abundance of the single-copy housekeeping gene recA (Finkel, Béjà \& Belkin, 2013; Brindefalk et al., 2016; Dubinsky et al., 2017) which is also used as a baseline for RNAseq normalization (Rocha, Santos \& Pacheco, 2015). The relative abundance of each of these genes in metatranscriptomes was then divided by their relative abundance in metagenomes to generate a normalized RNA to DNA ratio for each gene within each sample. Regardless of season or sampling location, the most common phototrophic mechanism in metagenomes was PR (65-104\% compared to recA), followed by PSI (5-104\%) and AAnP (5-32\%) (Fig. 2A). In fact, in 10 out of 12 samples the $P R$ gene exceeded $80 \%$ of $r e c A$ abundance (Fig. S5). PSI normalized gene abundance was variable while PR remained within a narrower range through the different seasons and stations (Fig. 2A, Fig. S6). The expression of both $P R$ and $p s a A$ was consistently 1-2 orders of magnitude higher than their respective gene abundance (Fig. $2 \mathrm{~B}$ ). The RNA to DNA ratio also revealed that while $p u f M$ gene abundance was sometimes comparable to psaA (Fig. 2A), its expression was 2-3 orders of magnitude lower (Fig. 2B). pufM expression was also 2-3 orders of magnitude lower than $p u f M$ gene abundance, suggesting that most of the AAnP bacteria in our samples were not actively performing this type of phototrophy at the time of sampling (Fig. 2B). Interestingly, we did not observe any geographical or seasonal trends for the presence of any light-harvesting strategies (Fig. 2).

The combined normalized relative abundance of PR and PSI exceeded $100 \%$ in all samples analyzed, suggesting multiple gene copy numbers or coexistence of these mechanisms within the same prokaryotic cells (Finkel, Béjà \& Belkin, 2013; Dubinsky et al., 2017), as previously shown in marine eukaryotic algae (Marchetti et al., 2012; Marchetti et al., 2015). While we did not observe any significant correlation between abundance of PR and PSI genes or transcripts, strong negative correlations between PR expression and total chlorophyll- $a$ (Chl- $a$ ) concentrations were clearly identified at POLA and SPOT (Fig. 3A), and attributed to SAR11 PR expression (Fig. 3B). No significant correlation was found between PR expression and any other nutrient measured (Table S1). PSI gene abundance as 


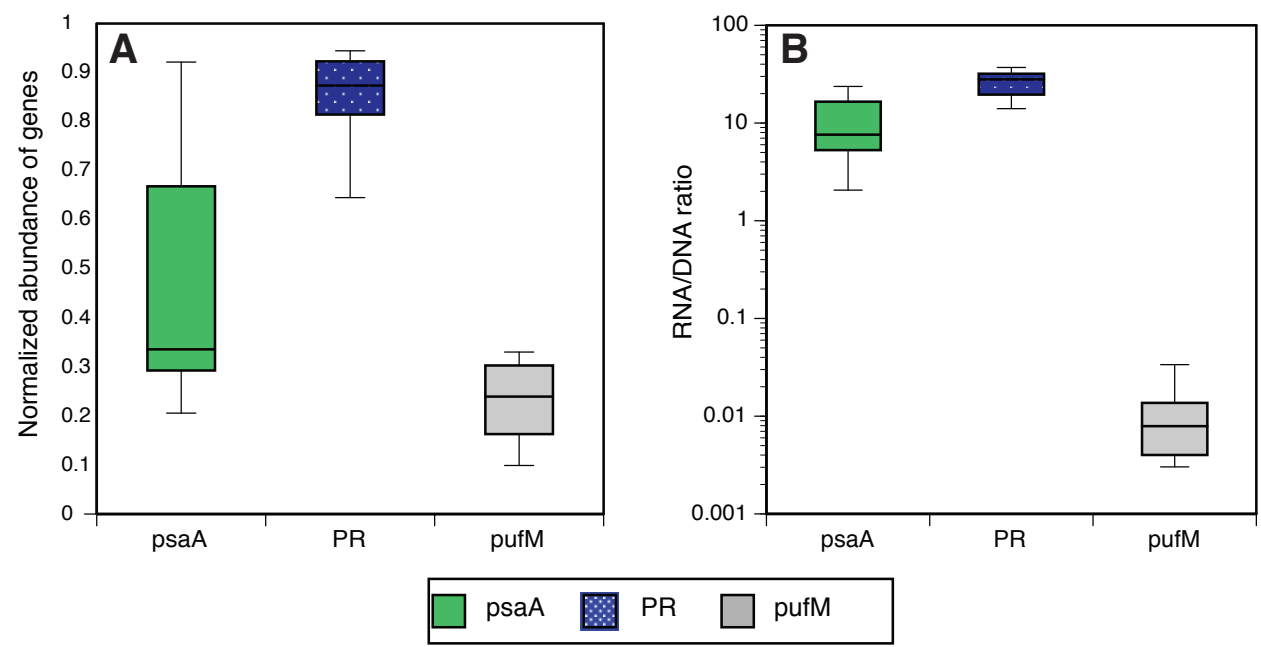

Figure 2 Normalized abundance and expression of phototrophic mechanisms. (A) Relative gene abundance of photosystem-I (PSI, psaA, green), rhodopsin (PR, dotted blue) and aerobic anoxygenic photosynthesis (AAnP, pufM, grey) normalized to recA in metagenomes and (B) RNA to DNA ratio per gene: the ratio between relative abundance out of all reads per sample in metatranscriptomes to relative abundance in metagenomes. Note that the $y$-axis in B is logarithmic.

Full-size DOI: 10.7717/peerj.5798/fig-2
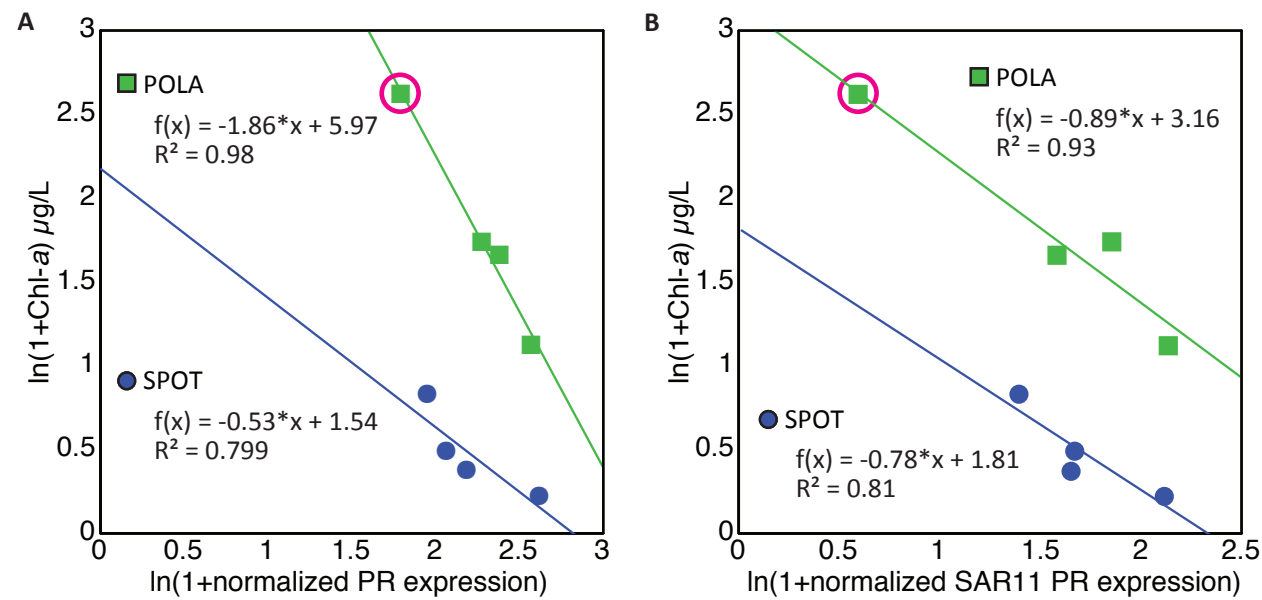

Figure 3 Negative correlation between proteorhodopsin (PR) expression and Chlorophyll-a at POLA and SPOT. (A) total PR expression (B) SAR11 PR-cluster expressionPR expression was normalized to recA expression. Trendline equations and $R^{2}$ values are indicated on the plot. No correlation was found in CAT. The point representing POLA April 2013 is circled on the plots.

Full-size DOI: $10.7717 /$ peerj.5798/fig-3

well as expression were dominated by cyanobacterial genes rather than eukaryotic, despite the placement of assembled PsaA from contigs into the eukaryotic clade in the phylogenetic tree of this protein (Fig. S1, Table S3). 


\section{PR distribution by cluster}

While our metagenomes revealed high taxonomic evenness of PR clusters (Fig. 4A, Fig. S7, average Shannon index of evenness $0.7 \pm 0.06$ ), expression was dominated by the SAR11 cluster $(52 \pm 14 \%)$ followed by Gammaproteobacteria $(15 \pm 6 \%)$, other Alphaproteobacteria (12 $\pm 7 \%)$ and unknown environmental clusters ( $8 \pm 2 \%)$ (Fig. 4B). Evenness in expression was always lower than evenness in gene abundance within a sample (one-sided paired $t$-test on Shannon index of evenness, $p=0.0003$ ) except at POLA in April 2013 (Fig. S7). This particular sample was collected during a localized algal bloom with the highest Chl- $a$ concentration measured in this study $\left(12.7 \mu \mathrm{gL}^{-1}\right)$. The AAnP RNA to DNA ratio in this sample was the highest we detected, and this was the only time in which expression of PSI surpassed that of PR (Fig. S5). PR expression in this sample was dominated by Gammaproteobacteria (30\%) and SAR11 PR expression dropped to 16\%.

\section{The SAR11 cluster}

We further examined the PR gene abundance and expression patterns of the SAR11 cluster, as this was the most abundant PR-containing group overall. SAR11 PR expression correlated positively with expression of SAR11 OTUs determined by 16S-rRNA (Fig. 5B). This correlation was also observed at the gene level after removing one outlier (POLA April 2013) (Fig. 5A). We further examined the presence and expression of specific SAR11 PR proteins within the SAR11 cluster by calculating read recruitment per leaf on the MicRhoDE phylogenetic tree of rhodopsins (Boeuf et al., 2015). We found that the high-resolution expression patterns were also much less even than gene distribution, where the top 10 most highly expressed leaves generally accounted for $>70 \%$ of the SAR11 PR transcripts compared to less than 50\% of gene abundance (Fig. 6). The mean Shannon index of evenness for gene abundance was $0.80 \pm 0.09$ (mean \pm standard deviation), and significantly lower for expression: $0.57 \pm 0.08$ (Wilcoxon rank sum test, paired one-sided, $p=0.0005)$. Only four of the 10 most expressed SAR11 PR transcripts were also in the 10 most abundant SAR11 PR genes (Figs. 6C, 6D).

\section{Other clusters}

Although we found 13 viral $\mathrm{PR}$ open reading frames (ORFs) in our assemblies, the viral PR cluster did not appear to be expressed in this system (no more than $2.2 \%$ of the total PR transcripts per sample). Archaeal clusters were extremely rare $(<1 \%$ of the metagenomic and $<2 \%$ of metatranscriptomic reads recruiting to PR).

Expression and gene abundance of eukaryotic PRs were not apparent in any of the samples. Most of the eukaryotes that are known to carry PRs, such as diatoms and dinoflagellates, are large and not expected to be present in our $<1 \mu \mathrm{m}$ size-fraction (Marchetti et al., 2015; Vader et al., 2018). The picoeukaryotes Micromonas spp. and Bathycoccus spp. that have been shown to contain PR genes and are sometimes found in the San Pedro Channel were not present in our small size-fraction samples.

\section{PR Spectral tuning}

We analyzed the spatiotemporal distribution of the two main PR variants (blue and green) in the metagenomes and compared our results to previously reported data (Brindefalk et al., 

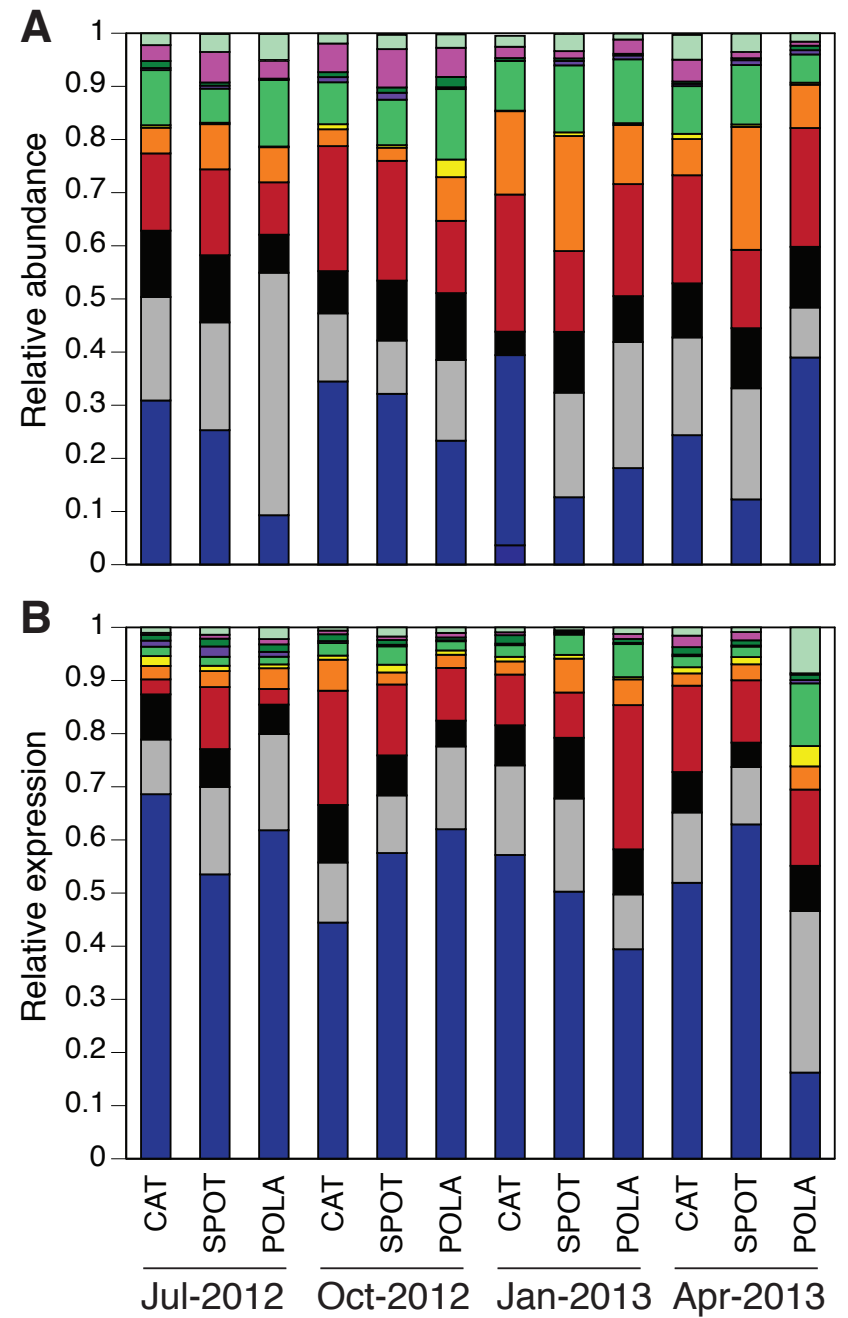

\begin{tabular}{|c|c|}
\hline SAR11 & Unknown Proteobacteria \\
\hline Gammaproteobacteria & Euryarchaea \\
\hline Unknown+environmental & Firmicutes \\
\hline Other Alphaproteobacteria & \\
\hline CFB & Viral \\
\hline Actinobacteria & Other clades \\
\hline
\end{tabular}

Figure 4 Relative abundance of various proteorhodopsins clusters (PR) out of all PR-assigned reads per sample. Relative abundance was calculated out of all rhodopsin-assigned reads per sample in (A) metagenomes (average $P R$ reads per sample 6,485, standard deviation 3,927) and (B) metatranscriptomes (average $P R$ reads per sample 43,005, standard deviation 22,367). The evenness of rhodopsin gene abundance was consistently high (see also sup. Fig. S7), whereas expression was dominated by SAR11 (dark blue), Gammaproteobacteria (grey), other Alphaproteobacteria (red) and unknown environmental clades 1 and 8 (black). The "Other clades" category includes rhodopsins of the MicRhoDE clusters Planctomycetes, bacteriorhodopsin, halorhodopsin, the "other rhodopsins" clade, NQ, xenorhodopsin, sensory rhodopsins, Betaproteobacteria, Deltaproteobacteria, Octadecabacter and Verrucomicrobia (Boeuf et al., 2015). 

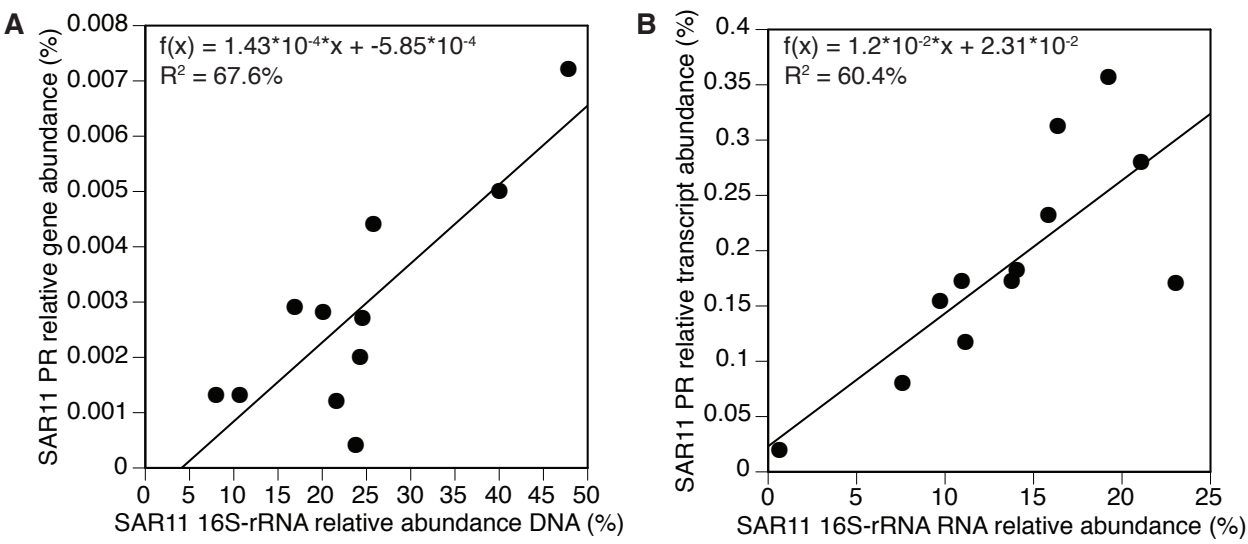

Figure 5 Positive correlation between 16S-rRNA and proteorhodopsin (PR) within the SAR11 clade. (A) Relative gene abundance and (B) relative transcript abundance. Sample collected at POLA in April 2013 was considered an outlier and therefore removed from the statistical analysis in (A).

Full-size DOI: 10.7717/peerj.5798/fig-5

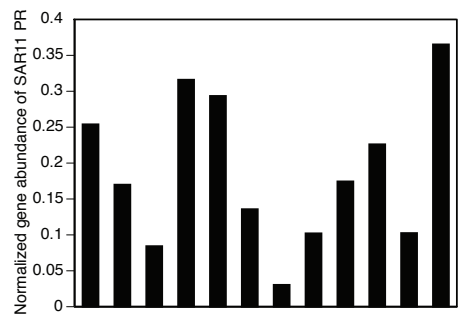

C

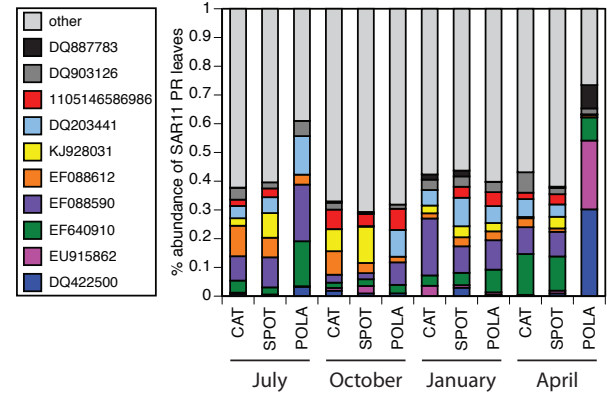

B
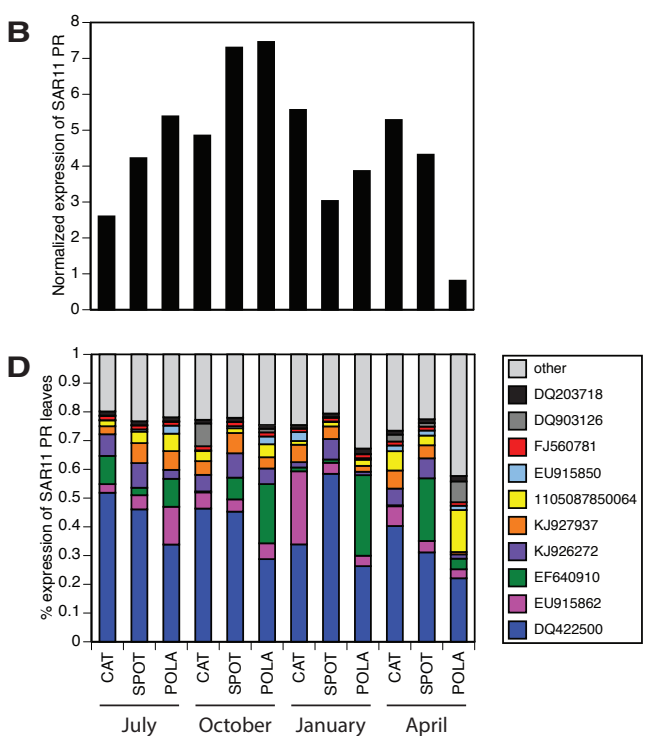

Figure 6 SAR11 cluster of proteorhodopsin (PR) at the single amino acid sequence level (per leaf in the MicRhoDE phylogenetic tree) had higher evenness in gene abundance than in expression (Wilcoxon rank sum test, paired one-sided, $\boldsymbol{p}=\mathbf{0 . 0 0 0 5}$ ). (A) SAR11 cluster PR total gene abundance over time and sites, (B) SAR11 cluster PR total expression over time and sites, (C) relative abundance of the 10 most abundant SAR11 cluster PR genes (all other SAR11 cluster PR were added up and represented as "other", total 12,852 reads) and (D) relative abundance of the 10 most highly expressed SAR11 cluster PR (total 185,019 reads). Note that $C$ and $D$ have separate legends and that only 4 PR leaves are shared between them. Leaves are denoted by accession numbers. 
A

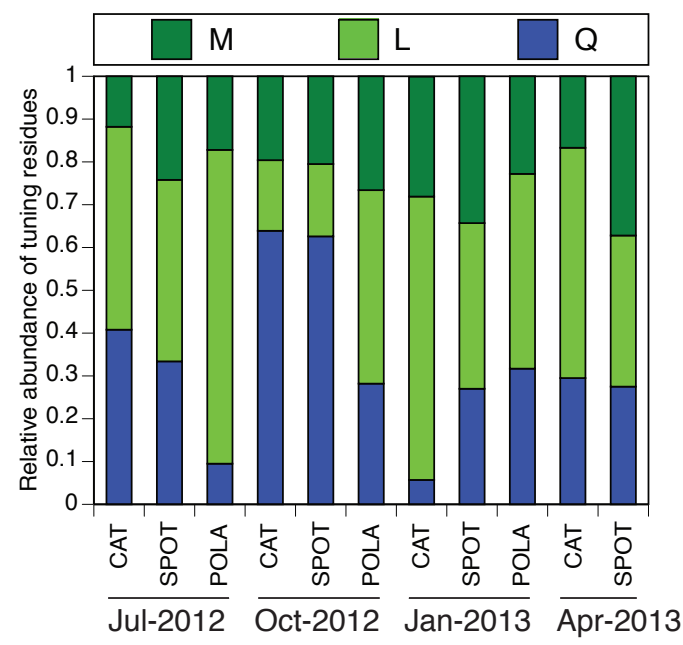

B

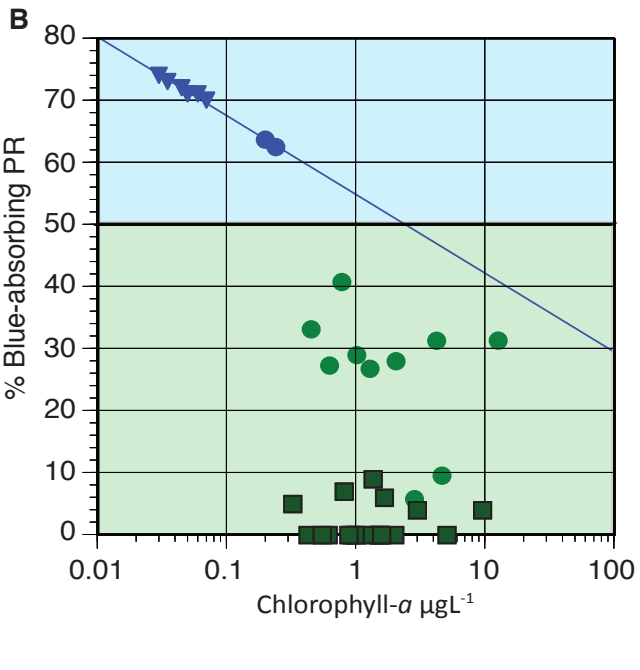

Figure 7 Spectral tuning of rhodopsins in our dynamic system and a comparison to previous studies. (A) Relative abundance of blue/green variants of proteorhodopsin (PR) in metagenomes (294-2,112 reads per sample): leucine (L) is represented by light green, methionine (M) by dark green and glutamine (Q) by blue. There was not enough data to plot tuning distribution at POLA in April 2013. (B) $0.25 \mu \mathrm{gL}^{-1}$ is the Chl- $a$ threshold between environments dominated by blue-tuned PR or green-tuned based on data from this paper and previous publications. Triangles, squares and circles denote data from Dubinsky et al. (2017), Brindefalk et al. (2016) and this study, respectively. The trendline for samples with Chl-a concentration below $0.25 \mu \mathrm{gL}^{-1}$ follows the equation \%Blue- $\mathrm{PR}=[-0.055 * \ln (\mathrm{Chl}-a)+0.55] * 100, R^{2}=0.99$. Full-size DOI: $10.7717 /$ peerj.5798/fig-7

2016; Dubinsky et al., 2017). Consistent with being a coastal environment, the majority of our samples were dominated by green-absorbing PR genes (Fig. 7A). However, samples collected at CAT and SPOT in October were dominated by the blue absorbing type, with $63 \%$ and $62 \%$ respectively. These two particular samples were collected on dates when Chl- $a$ levels were the lowest measured in this study, below $0.25 \mu \mathrm{gL}^{-1}$. Furthermore, the compilation of our data with values measured in the Eastern Mediterranean (Dubinsky et al., 2017) revealed a strong correlation between percent of blue-absorbing PR genes and the Chl- $a$ concentrations only below $0.25 \mu \mathrm{gL}^{-1}$ (Fig. 7B). However, the concentration of Chl- $a$ in the water is only one of the components that determine water color. To fully evaluate the role of the underwater light field in the spectral tuning of PR, we compared the proportion of green and blue PR gene variants to the corresponding satellite products of remote sensing reflectance ( $\mathrm{Rrs}$ ). The satellite remote sensing reflectance data shows predominantly blue reflectance spectra for all locations in July and October and green spectra in January and April (Fig. 8). In the week preceding sampling in July Rrs spectra indicated an algal bloom that disappeared by sampling day and during which blue light availability decreased (Fig. S8). 
A
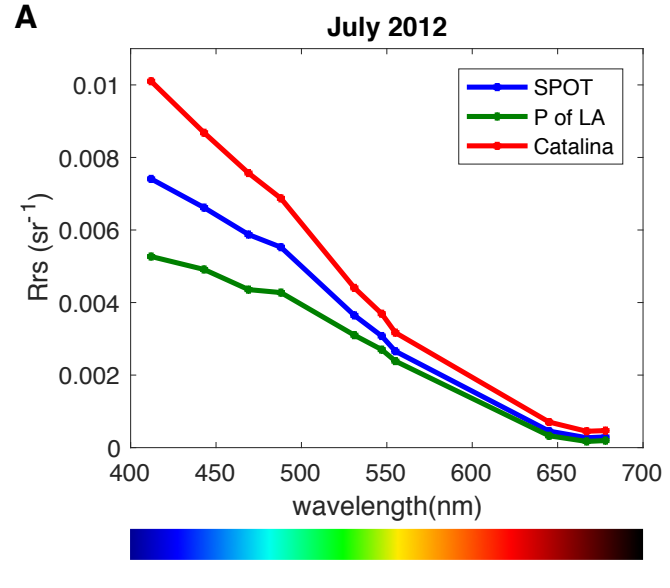

C

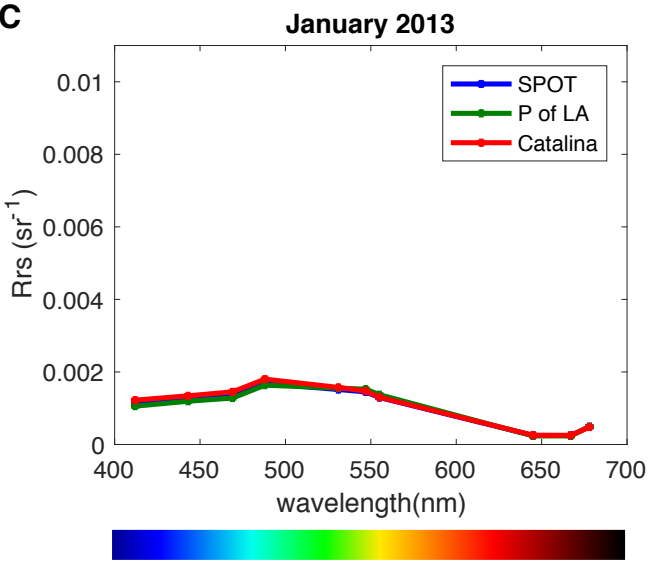

B

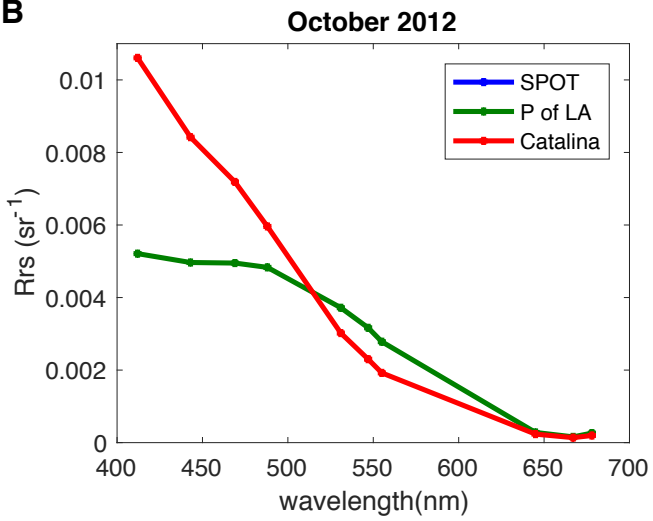

D

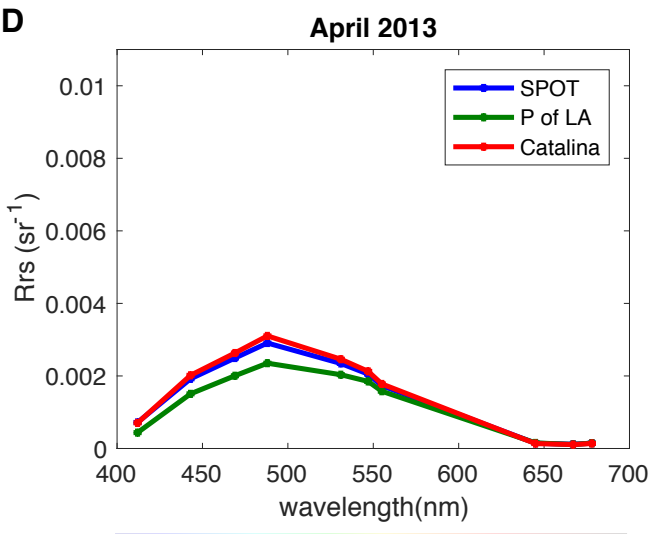

Figure 8 Remote sensing reflectance spectra (Rrs) per location and season. (A) July 16, 2012, (B) October 19, 2012, (C) January 10, 2012, (D) April 25, 2013. Measurements were taken the day after sampling day due to satellite data availability, with the exception of October for which there was data from the actual sampling day.

Full-size DOI: 10.7717/peerj.5798/fig-8

\section{DISCUSSION}

\section{PR dominates gene abundance and expression of picoplankton light-harvesting mechanisms year-round}

High abundance of PR genes was previously described in the Global Ocean Sampling data (Rusch et al., 2007) and in various other marine datasets (reviewed by Pinhassi et al., 2016; Brindefalk et al., 2016; Boeuf et al., 2016; Dubinsky et al., 2017; Maresca et al., 2018), and our observations further support this trend. However, most studies so far have focused on single time-points, and information on seasonal distribution of PR genes is lacking. Our experimental design allowed us to compare different contrasting locations and seasons, with the potential to identify patterns of phototrophy and resource availability. Previous studies in several marine environments (i.e., the North Atlantic and Arctic oceans as well as the Eastern Mediterranean Sea) found a correlation between PR gene abundance in genomes and Chl-a levels in seawater (Campbell et al., 2008; Boeuf et al., 2016; Dubinsky 
et al., 2017). Unexpectedly, we found that the presence of the PR gene in genomes was high year-round in this dynamic ecosystem, even at the eutrophic station of POLA, suggesting that the trophic state of the water is not always a good predictor of PR abundance.

PR expression in the San Pedro Channel was consistently higher than oxygenic photosynthesis in picoplankton over different seasons, with the exception of one sample taken during a localized algal bloom. A substantial amount of photosynthesis is performed by large photosynthetic eukaryotes and an important consideration is that AAnP bacteria and some cyanobacteria larger than $1 \mu \mathrm{m}$ or particle-attached are excluded from our analysis. Nevertheless, picoplankton $<1 \mu \mathrm{m}$ can, in fact, represent the majority of the photosynthetic community at SPOT and CAT (Connell et al., 2017; Needham, Sachdeva \& Fuhrman, 2017), and PR genes have been shown to be more abundant in this size fraction as well (Finkel, Béjà \& Belkin, 2013). Our results support the previously reported low gene abundances of aerobic anoxygenic photosynthesis (AAnP) (Boeuf et al., 2013; Boeuf et al., 2016; Dubinsky et al., 2017) but we further show that its expression is significantly lower compared to the other light-harvesting mechanisms. These results need to be taken with a grain of salt however, since the expression of genes in the puf cluster happens mostly during the night (Kobližek et al., 2003; Wagner-Döbler \& Biebl, 2006; Voget et al., 2015) and all our samples were collected in the early morning. Overall, we found no spatial trends in abundance or expression of PR genes, emphasizing the importance of this mechanism, but oxygenic photosynthesis and AAnP were significantly lower at POLA compared to the other stations. This highlights the importance of examining not just abundance of genes but also their expression when comparing these ubiquitous phototrophic strategies.

\section{PR expression is negatively correlated with chlorophyll-a concentrations}

Despite the co-occurrence of PR genes and oxygenic photosynthesis psaA genes, PR gene expression appeared to be negatively correlated to Chl- $a$ concentrations at SPOT and POLA. A similar trend was previously reported for gene abundance in the Arctic Ocean (Boeuf et al., 2016) and the Eastern Mediterranean (Dubinsky et al., 2017). Furthermore, this correlation was due to the expression trends of the SAR11 cluster of PR. We speculate that the slope of this correlation was steeper for total PR at POLA compared to SPOT due to the higher abundance of large photosynthetic eukaryotes at POLA (Connell et al., 2017), which can lead to more available organic carbon due to leaky cells and sloppy feeding. High availability of organic carbon enables cells to acquire energy heterotrophically rather than harvesting light, creating an environment in which the slow-growing oligotrophic-adapted SAR11 should be outcompeted (Giovannoni, 2017). To further support this, the slope of the correlation in SAR11 PR was similar between SPOT and POLA, implying that this clade is potentially not affected by high availability of labile carbon. Consistent with this hypothesis, in terms of physiology, PR phototrophy has been shown to be particularly important under DOM-limiting conditions typical of oligotrophic/low-chlorophyll regimes (Steindler et al., 2011; Gómez-Consarnau et al., 2007; Gómez-Consarnau et al., 2010; Gómez-Consarnau et al., 2016). This was especially clear at POLA in April 2013, when a localized diatom bloom was observed which did not extend to the other sites and led to a microbial eukaryotic 
community composition entirely divergent from all other samples (Hu et al., 2016; Connell et al., 2017). Notably, this was the only sample in which the expression of $p s a A$ genes for oxygenic photosynthesis exceeded that of PR genes. The high expression of $p s a A$ in this sample might be explained in part by the presence of chloroplasts released from diatoms that broke during the filtration and ended up being collected on the $0.2 \mu \mathrm{m}$ filter. As the cumulative abundance of photosynthetic eukaryotes was significantly higher in this particular sample (Connell et al., 2017), and the relative abundance of diatom 18S DNA and RNA in it was higher than or equal to that of all other samples combined, this artifact is much more likely to have occurred in this sample. While the relative abundance of PR genes by clusters in this sample was similar to others, the expression pattern demonstrated an exchange of dominance between SAR11 and Gammaproteobacteria, most likely as a succession response to the algal bloom (Needham \& Fuhrman, 2016).

\section{SAR11 is the most highly expressed PR cluster}

Owing to the differences between the present PR-bearing community and its active subset, PR gene abundance distribution by cluster was more even at the gene level, as earlier observed in the Red Sea (Philosof \& Béjà, 2013). The SAR11-cluster of proton-pump type PR dominated PR transcripts. Furthermore, the expression of this cluster correlated positively with the expression of SAR11 16S-rRNA operational taxonomic units (OTUs, 99\% identity). This correlation was maintained at the gene level with the exception of POLA in April, potentially due to the interference introduced by the diatom bloom. These matching trends of presence and expression of the SAR11 PR aligns with the streamlined nature of SAR11 genomes and their reported constitutive expression of this protein (Giovannoni et al., 2005).

Other rhodopsins (e.g., actinorhodopsin, bacteriorhodopsin, xanthorhodopsin, halorhodopsin and xenorhodopsin) were rare. The abundance and expression of viral PRs was also very low, consistent with the fact that viral PRs were so far detected only in giant Phycodnaviruses of freshwater eukaryotes (Yutin \& Koonin, 2012) and in low-salinity water (Brindefalk et al., 2016). While there is an inherent problem with normalizing both abundance and expression of viral PRs, as there are no universal viral marker genes to normalize to, this limitation was unlikely to affect our results due to the low relative abundance of viral PR. However, this should be taken into account in studies where the viral PR cluster is better represented.

\section{PR spectral tuning has a key role in population dynamics}

Some studies show that blue light absorbing PR variants dominate in open ocean, oligotrophic conditions, whereas the green variants are more abundant in shallow or coastal water (Man et al., 2003; Rusch et al., 2007). However, these observations are not consistent in the literature, since the different PR types were also found to be decoupled from water parameters (Sabehi et al., 2007). As conditions at SPOT and CAT are dynamic and fluctuate seasonally between oligotrophic and mesotrophic conditions (Cram et al., 2015; Connell et al., 2017), we expected the spectral tuning of PRs to vary throughout the year. We observed a majority of blue absorbing PRs only in October of 2012, which 
coincided with the lowest Chl- $a$ concentrations recorded in this study. Additionally, despite similar availability of blue light in July and October, PR tuning was dominated by the blue variant only in October. It is possible that the presence of an algal bloom during the week before sampling in July led to dominance of the green variant which the system did not recover from by sampling day. Comparing our results with published data from the ultraoligotrophic Eastern Mediterranean Sea (Chl- $a<0.01 \mu \mathrm{gL}^{-1}$, (Dubinsky et al., 2017), we observed a Chl-a concentration pivot point of about $0.25 \mu \mathrm{gL}^{-1}$. When Chl- $a$ concentration was below this threshold, as in the Mediterranean and at SPOT and CAT in October, there was a highly significant negative correlation of chlorophyll concentration with PR expression, as well as high (60-75\%) percent blue absorption at the gene level. However, above this threshold the percentage of cells with the blue variant PR genes dropped to an average of about $30 \%$ with no clear correlation to Chl-a. Similarly, Brindefalk et al. (2016) found even higher relative abundances of the green PR gene variant (>90\%) in the Baltic Sea (Brindefalk et al., 2016) co-occurring with Chl-a levels significantly above $0.25 \mu \mathrm{gL}^{-1}$. However, Chl- $a$ concentration is only a proxy for the quality and quantity of light in the water column and the dissolved organic material (DOM) available. Under bloom conditions, Chl- $a$ concentrations increase, turning the water greener and reducing its transparency. The consequent increase in available DOM that follows blooms further attenuates light in the water column, particularly in the blue and UV region of the spectrum. The resulting combination of reflectance and absorption by algal pigments, dissolved organic matter, water and inorganic particles is what determines the available light in the water column. When DOM is low, light harvesting and spectral tuning of PR may play a crucial role in survival or fitness of photoheterotrophic bacterial populations. This is evident in the most oligotrophic locations such as the Eastern Mediterranean (Dubinsky et al., 2017). Consistent with this, in year-round eutrophic locations such as the Baltic Sea, the dominant variant is green whereas in dynamic locations such as SPOT and POLA, a mix of the two variants can be expected. Since we can readily identify these patterns at the gene level, our data suggests that the light regime is a key factor driving selection in PR-containing populations, as suggested in the past (Sabehi et al., 2007). Since we did not collect in situ DOM or irradiance measurements, future studies will be needed to better define and increase the resolution of these thresholds to better understand the role of light quality and availability in population dynamics, survival and competition.

\section{CONCLUSION}

Our spatial time-series analysis of PR and oxygenic and anoxygenic photosynthesis in marine picoplankton revealed that (1) expression of PR-based photoheterotrophy exceeded that of oxygenic photoautotrophy, (2) PR expression was dominated by few clusters despite a more even presence of diverse PR clusters, and (3) aerobic anoxygenic photosynthesis gene abundance appears to be relatively rare compared to the other mechanisms in this system. It is highly important to continue collecting more deeply-sequenced metatranscriptomic data in order to begin to elucidate the local adaptations of photoheterotrophs in the ocean that 
lead to their global success. Finally, our results reinforce the conclusion that the differences in the light spectrum are an important selective force, defining the abundance of different PR photoheterotrophic types.

\section{ACKNOWLEDGEMENTS}

The authors would like to thank Dominique Boeuf for kindly providing supporting files for phylogenetic tree analysis, to Jose M. Gonzalez for providing additional PR protein sequences and to Elaina D. Graham for bioinformatic advice. We would like to thank Erin Beers-Fichot for her help in the sampling cruises and metatranscriptome generation, as well as Catherine Roney-Garcia, Alma Parada, Jacob Cram, David Needham and the Sundiver crew for their assistance in cruises and sample processing. We would also like to thanks the Caron lab (USC) for Chlorophyll- $a$ measurements. The authors acknowledge the USC Wrigley Institute of Environmental Studies. Finally, we would like to thank the three anonymous reviewers for their constructive comments which helped improve the manuscript.

\section{ADDITIONAL INFORMATION AND DECLARATIONS}

\section{Funding}

This work was funded by NSF grants OCE1335269,1136818 and OCE-1323319, as well as by the Gordon and Betty Moore Foundation Marine Microbiology Initiative grant GBMF3779. The funders had no role in study design, data collection and analysis, decision to publish, or preparation of the manuscript.

\section{Grant Disclosures}

The following grant information was disclosed by the authors:

NSF: OCE1335269, 1136818, OCE-1323319.

Gordon and Betty Moore Foundation Marine Microbiology Initiative: GBMF3779.

\section{Competing Interests}

The authors declare there are no competing interests.

\section{Author Contributions}

- Ella T. Sieradzki conceived and designed the experiments, performed the experiments, analyzed the data, prepared figures and/or tables, authored or reviewed drafts of the paper, approved the final draft.

- Jed A. Fuhrman conceived and designed the experiments, contributed reagents/materials/analysis tools, authored or reviewed drafts of the paper, approved the final draft.

- Sara Rivero-Calle analyzed the data, contributed reagents/materials/analysis tools, prepared figures and/or tables, authored or reviewed drafts of the paper, approved the final draft.

- Laura Gómez-Consarnau conceived and designed the experiments, analyzed the data, prepared figures and/or tables, authored or reviewed drafts of the paper, approved the final draft. 


\section{Data Availability}

The following information was supplied regarding data availability:

All raw data (16S/18S, metagenomes and metatranscriptomes) can be found on EMBL-ENA under project number PRJEB12234. Metatranscriptomics sequences accession numbers are ERS1864892-ERS1864903, and negative control library sequences accession number is ERR2089009. Metagenomic sequences accession numbers are ERS1869885ERS1869896 and negative control accession number is ERS1872073.

Assembled amino acid sequences of Prd, PsaA and RecA can be found at Sieradzki, Ella (2018): Dimensions of Biodiversity—San Pedro Channel. figshare. Collection. https://doi.org/10.6084/m9.figshare.c.4099757.v1.

\section{Supplemental Information}

Supplemental information for this article can be found online at http://dx.doi.org/10.7717/ peerj.5798\#supplemental-information.

\section{REFERENCES}

Béjà O, Aravind L, Koonin EV, Suzuki MT, Hadd A, Nguyen LP, Jovanovich SB, Gates CM, Feldman RA, Spudich JL, Spudich EN, DeLong EF. 2000. Bacterial rhodopsin: evidence for a new type of phototrophy in the sea. Science 289(5486):1902-1906 DOI 10.1126/science.289.5486.1902.

Béjà O, Spudich EN, Spudich JL, Leclerc M, DeLong EF. 2001. Proteorhodopsin phototrophy in the ocean. Nature 411(6839):786-789 DOI 10.1038/35081051.

Boeuf D, Audic S, Brillet-Guéguen L, Caron C, Jeanthon C. 2015. MicRhoDE: a curated database for the analysis of microbial rhodopsin diversity and evolution. Database 2015:Article bav080 DOI 10.1093/database/bav080.

Boeuf D, Cottrell MT, Kirchman DL, Lebaron P, Jeanthon C. 2013. Summer community structure of aerobic anoxygenic phototrophic bacteria in the western Arctic Ocean. FEMS Microbiology Ecology 85(3):417-432 DOI 10.1111/1574-6941.12130.

Boeuf D, Lami R, Cunnington E, Jeanthon C. 2016. Summer abundance and distribution of proteorhodopsin genes in the Western Arctic Ocean. Frontiers in Microbiology 7:Article 1584.

Bolger AM, Lohse M, Usadel B. 2014. Trimmomatic: a flexible trimmer for Illumina sequence data. Bioinformatics 30(15):2114-2120 DOI 10.1093/bioinformatics/btu170.

Brindefalk B, Ekman M, Ininbergs K, Dupont CL, Yooseph S, Pinhassi J, Bergman B. 2016. Distribution and expression of microbial rhodopsins in the Baltic Sea and adjacent waters. Environmental Microbiology 18(12):4442-4455 DOI 10.1111/1462-2920.13407.

Camacho C, Coulouris G, Avagyan V, Ma N, Papadopoulos J, Bealer K, Madden TL. 2009. BLAST+: architecture and applications. BMC Bioinformatics 10(1):421 DOI 10.1186/1471-2105-10-421.

Campbell BJ, Waidner LA, Cottrell MT, Kirchman DL. 2008. Abundant proteorhodopsin genes in the North Atlantic Ocean. Environmental Microbiology 10(1):99-109. 
Caporaso JG, Kuczynski J, Stombaugh J, Bittinger K, Bushman FD, Costello EK, Fierer N, Peña AG, Goodrich JK, Gordon JI, Huttley GA, Kelley ST, Knights D, Koenig JE, Ley RE, Lozupone CA, McDonald D, Muegge BD, Pirrung M, Reeder J, Sevinsky JR, Turnbaugh PJ, Walters WA, Widmann J, Yatsunenko T, Zaneveld J, Knight R. 2010. QIIME allows analysis of high-throughput community sequencing data. Nature Methods 7(5):335-336 DOI 10.1038/nmeth.f.303.

Castresana J. 2000. Selection of conserved blocks from multiple alignments for their use in phylogenetic analysis. Molecular Biology and Evolution 17(4):540-552 DOI 10.1093/oxfordjournals.molbev.a026334.

Connell PE, Campbell V, Gellene AG, Hu SK, Caron DA. 2017. Planktonic food web structure at a coastal time-series site: II. Spatiotemporal variability of microbial trophic activities. Deep Sea Research Part I: Oceanographic Research Papers 121:210-223 DOI 10.1016/j.dsr.2017.01.007.

Cram JA, Chow CET, Sachdeva R, Needham DM, Parada AE, Steele JA, Fuhrman JA. 2015. Seasonal and interannual variability of the marine bacterioplankton community throughout the water column over ten years. The ISME Journal 9(3):563 DOI 10.1038/ismej.2014.153.

Dubinsky V, Haber M, Burgsdorf I, Saurav K, Lehahn Y, Malik A, Sher D, Aharonovich D, Steindler L. 2017. Metagenomic analysis reveals unusually high incidence of proteorhodopsin genes in the ultraoligotrophic Eastern Mediterranean Sea. Environmental Microbiology 19(3):1077-1090 DOI 10.1111/1462-2920.13624.

Edgar RC. 2010. Search and clustering orders of magnitude faster than BLAST. Bioinformatics 26(19):2460-2461 DOI 10.1093/bioinformatics/btq461.

Eren AM, Esen ÖC, Quince C, Vineis JH, Morrison HG, Sogin ML, Delmont TO. 2015. Anvi'o: an advanced analysis and visualization platform for 'omics data. PeerJ 3:e1319 DOI 10.7717/peerj.1319.

Feng S, Powell SM, Wilson R, Bowman JP. 2013. Light-stimulated growth of proteorhodopsin-bearing sea-ice psychrophile Psychroflexus torquis is salinity dependent. The ISME Journal 7(11):2206-2213 DOI 10.1038/ismej.2013.97.

Finkel OM, Béjà O, Belkin S. 2013. Global abundance of microbial rhodopsins. The ISME Journal 7(2):448-451 DOI 10.1038/ismej.2012.112.

Finn RD, Coggill P, Eberhardt RY, Eddy SR, Mistry J, Mitchell AL, Potter SC, Punta M, Qureshi M, Sangrador-Vegas A, Salazar GA, Tate J, Bateman A. 2016. The Pfam protein families database: towards a more sustainable future. Nucleic Acids Research 44(D1):D279-D285 DOI 10.1093/nar/gkv1344.

Frias-Lopez J, Shi Y, Tyson GW, Coleman ML, Schuster SC, Chisholm SW, DeLong EF. 2008. Microbial community gene expression in ocean surface waters. Proceedings of the National Academy of Sciences of the United States of America 105(10):3805-3810 DOI 10.1073/pnas.0708897105.

Fu L, Niu B, Zhu Z, Wu S, Li W. 2012. CD-HIT: accelerated for clustering the nextgeneration sequencing data. Bioinformatics 28(23):3150-3152

DOI 10.1093/bioinformatics/bts565. 
Fuhrman JA, Schwalbach MS, Stingl U. 2008. Proteorhodopsins: an array of physiological roles? Nature Reviews Microbiology 6(6):488-494 DOI 10.1038/nrmicro1893.

Giovannoni SJ. 2017. SAR11 bacteria: the most abundant plankton in the oceans. Annual Review of Marine Science 9:231-255 DOI 10.1146/annurev-marine-010814-015934.

Giovannoni SJ, Tripp HJ, Givan S, Podar M, Vergin KL, Baptista D, Bibbs L, Eads J, Richardson TH, Noordewier M, Rappé MS, Short JM, Carrington JC, Mathur EJ. 2005. Genome streamlining in a cosmopolitan oceanic bacterium. Science 309(5738):1242-1245 DOI 10.1126/science.1114057.

Gómez-Consarnau L, Akram N, Lindell K, Pedersen A, Neutze R, Milton DL, González JM, Pinhassi J. 2010. Proteorhodopsin phototrophy promotes survival of marine bacteria during starvation. PLOS Biology 8(4):e1000358 DOI 10.1371/journal.pbio.1000358.

Gómez-Consarnau L, González JM, Coll-Lladó M, Gourdon P, Pascher T, Neutze R, Pedrós-Alió C, Pinhassi J. 2007. Light stimulates growth of proteorhodopsincontaining marine Flavobacteria. Nature 445(7124):210-213

DOI 10.1038/nature05381.

Gómez-Consarnau L, González JM, Riedel T, Jaenicke S, Wagner-Döbler I, Sañudo Wilhelmy SA, Fuhrman JA. 2016. Proteorhodopsin light-enhanced growth linked to vitamin-B1 acquisition in marine Flavobacteria. The ISME Journal 10(5):1102-1112 DOI 10.1038/ismej.2015.196.

Gómez-Pereira PR, Hartmann M, Grob C, Tarran GA, Martin AP, Fuchs BM, Scanlan DJ, Zubkov MV. 2013. Comparable light stimulation of organic nutrient uptake by SAR11 and Prochlorococcus in the North Atlantic subtropical gyre. The ISME Journal 7(3):603-614 DOI 10.1038/ismej.2012.126.

Hu SK, Campbell V, Connell P, Gellene AG, Liu Z, Terrado R, Caron DA. 2016. Protistan diversity and activity inferred from RNA and DNA at a coastal ocean site in the eastern North Pacific. FEMS Microbiology Ecology 92(4):Article fiw050.

Hyatt D, Chen GL, LoCascio PF, Land ML, Larimer FW, Hauser LJ. 2010. Prodigal: prokaryotic gene recognition and translation initiation site identification. BMC Bioinformatics 11(1):119 DOI 10.1186/1471-2105-11-119.

Ignacio-Espinoza JC, Sullivan MB. 2012. Phylogenomics of T4 cyanophages: lateral gene transfer in the 'core' and origins of host genes. Environmental Microbiology 14(8):2113-2126 DOI 10.1111/j.1462-2920.2012.02704.x.

Johnson LS, Eddy SR, Portugaly E. 2010. Hidden Markov model speed heuristic and iterative HMM search procedure. BMC Bioinformatics 11(1):431 DOI 10.1186/1471-2105-11-431.

Kahle D, Wickham H. 2013. ggmap: spatial Visualization with ggplot2. $R$ Journal 5(1):144-161.

Katoh K, Standley DM. 2013. MAFFT multiple sequence alignment software version 7: improvements in performance and usability. Molecular Biology and Evolution 30(4):772-780 DOI 10.1093/molbev/mst010. 
Koblížek M, Béjà O, Bidigare RR, Christensen S, Benitez-Nelson B, Vetriani C, Kolber MK, Falkowski PG, Kolber ZS. 2003. Isolation and characterization of Erythrobacter sp. strains from the upper ocean. Archives of Microbiology 180(5):327-338 DOI 10.1007/s00203-003-0596-6.

Kopf A, Kostadinov I, Wichels A, Quast C, Glöckner FO. 2015. Metatranscriptome of marine bacterioplankton during winter time in the North Sea assessed by total RNA sequencing. Marine Genomics 19:45-46 DOI 10.1016/j.margen.2014.11.001.

Kozich JJ, Westcott SL, Baxter NT, Highlander SK, Schloss PD. 2013. Development of a dual-index sequencing strategy and curation pipeline for analyzing amplicon sequence data on the MiSeq illumina sequencing platform. Applied and Environmental Microbiology 79(17):5112-5120 DOI 10.1128/AEM.01043-13.

Li D, Liu C-M, Luo R, Sadakane K, Lam T-W. 2015. MEGAHIT: an ultra-fast singlenode solution for large and complex metagenomics assembly via succinct de Bruijn graph. Bioinformatics 31(10):1674-1676 DOI 10.1093/bioinformatics/btv033.

Man D, Wang W, Sabehi G, Aravind L, Post AF, Massana R, Spudich EN, Spudich JL, Béjà O. 2003. Diversification and spectral tuning in marine proteorhodopsins. The EMBO Journal 22(8):1725-1731 DOI 10.1093/emboj/cdg183.

Marchetti A, Catlett D, Hopkinson BM, Ellis K, Cassar N. 2015. Marine diatom proteorhodopsins and their potential role in coping with low iron availability. The ISME Journal 9(12):2745-2748 DOI 10.1038/ismej.2015.74.

Marchetti A, Schruth DM, Durkin CA, Parker MS, Kodner RB, Berthiaume CT, Morales R, Allen AE, Armbrust EV. 2012. Comparative metatranscriptomics identifies molecular bases for the physiological responses of phytoplankton to varying iron availability. Proceedings of the National Academy of Sciences 109(6):E317-E325.

Maresca JA, Miller KJ, Keffer JL, Sabanayagam CR, Campbell BJ. 2018. Distribution and diversity of rhodopsin-producing microbes in the Chesapeake Bay. Applied and Environmental Microbiology 84(13):e00137-18.

Margulies M, Egholm M, Altman WE, Attiya S, Bader JS, Bemben LA, Berka J, Braverman MS, Chen Y-J, Chen Z, Dewell SB, Du L, Fierro JM, Gomes XV, Goodwin BC, He W, Helgesen S, He Ho C, Irzyk GP, Jando SC, Alenquer MLI, Jarvie TP, Jirage KB, Kim J-B, Knight JR, Lanza JR, Leamon JH, Lefkowitz SM, Lei M, Li J, Lohman KL, Lu H, Makhijani VB, McDade KE, McKenna MP, Myers EW, Nickerson E, Nobile JR, Plant R, Puc BP, Ronan MT, Roth GT, Sarkis GJ, Simons JF, Simpson JW, Srinivasan M, Tartaro KR, Tomasz A, Vogt KA, Volkmer GA, Wang SH, Wang Y, Weiner MP, Yu P, Begley RF, Rothberg JM. 2005. Genome sequencing in open microfabricated high density picoliter reactors. Nature 437(7057):376-380 DOI 10.1038/nature03959.

Martinez-Hernandez F, Fornas O, Gomez ML, Bolduc B, De La Cruz Peña MJ, Martínez JM, Anton J, Gasol JM, Rosselli R, Rodriguez-Valera F, Sullivan MB, Acinas SG, Martinez-Garcia M. 2017. Single-virus genomics reveals hidden cosmopolitan and abundant viruses. Nature Communications 8:Article 15892 DOI 10.1038/ncomms15892. 
Matsen FA, Kodner RB, Armbrust EV. 2010. pplacer: linear time maximum-likelihood and Bayesian phylogenetic placement of sequences onto a fixed reference tree. $B M C$ Bioinformatics 11(1):538 DOI 10.1186/1471-2105-11-538.

Needham DM, Fuhrman JA. 2016. Pronounced daily succession of phytoplankton, archaea and bacteria following a spring bloom. Nature Microbiology 1(4):Article 16005 DOI 10.1038/nmicrobiol.2016.5.

Needham DM, Sachdeva R, Fuhrman JA. 2017. Ecological dynamics and co-occurrence among marine phytoplankton, bacteria and myoviruses shows microdiversity matters. The ISME Journal 11(7):1614-1629.

Nguyen D, Maranger R, Balagué V, Coll-Llado M, Lovejoy C, Pedros-Alio C. 2015. Winter diversity and expression of proteorhodopsin genes in a polar ocean. The ISME Journal 9(8):1835-1845 DOI 10.1038/ismej.2015.1.

Noble RT, Fuhrman JA. 1998. Use of SYBR Green I for rapid epifluorescence counts of marine viruses and bacteria. Aquatic Microbial Ecology 14(2):113-118 DOI 10.3354/ame014113.

Ottesen EA, Young CR, Gifford SM, Eppley JM, Marin R, Schuster SC, Scholin CA, DeLong EF. 2014. Multispecies diel transcriptional oscillations in open ocean heterotrophic bacterial assemblages. Science 345(6193):207-212 DOI 10.1126/science.1252476.

Parada AE, Needham DM, Fuhrman JA. 2016. Every base matters: assessing small subunit rRNA primers for marine microbiomes with mock communities, time series and global field samples. Environmental Microbiology 18(5):1403-1414 DOI 10.1111/1462-2920.13023.

Patel A, Noble RT, Steele JA, Schwalbach MS, Hewson I, Fuhrman JA. 2007. Virus and prokaryote enumeration from planktonic aquatic environments by epifluorescence microscopy with SYBR Green I. Nature Protocols 2(2):269-276 DOI 10.1038/nprot.2007.6.

Philosof A, Béjà O. 2013. Bacterial, archaeal and viral-like rhodopsins from the Red Sea. Environmental Microbiology Reports 5(3):475-482 DOI 10.1111/1758-2229.12037.

Pinhassi J, DeLong EF, Béjà O, González JM, Pedrós-Alió C. 2016. Marine bacterial and archaeal ion-pumping rhodopsins: genetic diversity, physiology, and ecology. Microbiology and Molecular Biology Reviews 80(4):929-954 DOI 10.1128/MMBR.00003-16.

Poretsky RS, Hewson I, Sun S, Allen AE, Zehr JP, Moran MA. 2009. Comparative day/night metatranscriptomic analysis of microbial communities in the North Pacific subtropical gyre. Environmental Microbiology 11(6):1358-1375 DOI 10.1111/j.1462-2920.2008.01863.x.

R package psych. 2018. Available at https://cran.r-project.org/web/packages/psych/psych. $p d f$.

R package RAM. 2018. Available at https://cran.r-project.org/web/packages/RAM/index. html.

Riedel T, Tomasch J, Buchholz I, Jacobs J, Kollenberg M, Gerdts G, Wichels A, Brinkhoff T, Cypionka H, Wagner-Döbler I. 2010. Constitutive expression of the proteorhodopsin gene by a flavobacterium strain representative of the 
proteorhodopsin-producing microbial community in the North Sea. Applied and Environmental Microbiology 76(10):3187-3197.

Rocha DJ, Santos CS, Pacheco LG. 2015. Bacterial reference genes for gene expression studies by RT-qPCR: survey and analysis. Antonie Van Leeuwenhoek 108(3):685-693 DOI 10.1007/s10482-015-0524-1.

Rusch DB, Halpern AL, Sutton G, Heidelberg KB, Williamson S, Yooseph S, Wu D, Eisen JA, Hoffman JM, Remington K, Beeson K, Tran B, Smith H, BadenTillson H, Stewart C, Thorpe J, Freeman J, Andrews-Pfannkoch C, Venter JE, Li K, Kravitz S, Heidelberg JF, Utterback T, Rogers Y-H, Falcón LI, Souza V, Bonilla-Rosso G, Eguiarte LE, Karl DM, Sathyendranath S, Platt T, Bermingham E, Gallardo V, Tamayo-Castillo G, Ferrari MR, Strausberg RL, Nealson K, Friedman R, Frazier M, Venter JC. 2007. The Sorcerer II global ocean sampling expedition: northwest Atlantic through eastern tropical Pacific. PLOS Biology 5(3):e77 DOI 10.1371/journal.pbio.0050077.

Sabehi G, Béjà O, Suzuki MT, Preston CM, DeLong EF. 2004. Different SAR86 subgroups harbour divergent proteorhodopsins. Environmental Microbiology 6(9):903-910 DOI 10.1111/j.1462-2920.2004.00676.x.

Sabehi G, Kirkup BC, Rozenberg M, Stambler N, Polz MF, Béjà O. 2007. Adaptation and spectral tuning in divergent marine proteorhodopsins from the eastern Mediterranean and the Sargasso Seas. The ISME Journal 1(1):48-55 DOI 10.1038/ismej.2007.10.

Satinsky BM, Crump BC, Smith CB, Sharma S, Zielinski BL, Doherty M, Meng J, Sun S, Medeiros PM, Paul JH, Coles VJ, Yager PL, Moran MA. 2014. Microspatial gene expression patterns in the Amazon River Plume. Proceedings of the $\mathrm{Na}$ tional Academy of Sciences of the United States of America 111(30):11085-11090 DOI 10.1073/pnas.1402782111.

Shi Y, Tyson GW, Eppley JM, DeLong EF. 2011. Integrated metatranscriptomic and metagenomic analyses of stratified microbial assemblages in the open ocean. The ISME Journal 5(6):999-1013 DOI 10.1038/ismej.2010.189.

Sommer DD, Delcher AL, Salzberg SL, Pop M. 2007. Minimus: a fast, lightweight genome assembler. BMC Bioinformatics 8(1):64 DOI 10.1186/1471-2105-8-64.

Stamatakis A. 2014. RAxML version 8: a tool for phylogenetic analysis and post-analysis of large phylogenies. Bioinformatics 30(9):1312-1313

DOI 10.1093/bioinformatics/btu033.

Steindler L, Schwalbach MS, Smith DP, Chan F, Giovannoni SJ. 2011. Energy starved Candidatus Pelagibacter ubique substitutes light-mediated ATP production for endogenous carbon respiration. PLOS ONE 6(5):e19725

DOI 10.1371/journal.pone.0019725.

Vader A, Laughinghouse IV HD, Griffiths C, Jakobsen KS, Gabrielsen TM. 2018. Proton-pumping rhodopsins are abundantly expressed by microbial eukaryotes in a high-Arctic fjord. Environmental Microbiology 20(2):890-902 DOI 10.1111/1462-2920.14035. 
Voget S, Wemheuer B, Brinkhoff T, Vollmers J, Dietrich S, Giebel HA, Beardsley C, Sardemann C, Bakenhus I, Billerbeck S, Daniel R, Simon M. 2015. Adaptation of an abundant Roseobacter RCA organism to pelagic systems revealed by genomic and transcriptomic analyses. The ISME Journal 9(2):371-384 DOI 10.1038/ismej.2014.134.

Wagner-Döbler I, Biebl H. 2006. Environmental biology of the marine Roseobacter lineage. Annual Review of Microbiology 60:255-280

DOI 10.1146/annurev.micro.60.080805.142115.

Walter JM, Greenfield D, Bustamante C, Liphardt J. 2007. Light-powering Escherichia coli with proteorhodopsin. Proceedings of the National Academy of Sciences of the United States of America 104(7):2408-2412 DOI 10.1073/pnas.0611035104.

Welschmeyer NA, Naughton SL. 1994. Improved chlorophyll a analysis: single fluorometric measurement with no acidification. Lake and Reservoir Management 9(2):123.

Yilmaz P, Parfrey LW, Yarza P, Gerken J, Pruesse E, Quast C, Schweer T, Peplies J, Ludwig W, Glöckner FO. 2013. The SILVA and all-species living tree project (LTP) taxonomic frameworks. Nucleic Acids Research 42(D1):D643-D648.

Yutin N, Koonin EV. 2012. Proteorhodopsin genes in giant viruses. Biology Direct 7(1):Article 34 DOI 10.1186/1745-6150-7-34.

Zhang J, Kobert K, Flouri T, Stamatakis A. 2013. PEAR: a fast and accurate illumina paired-end reAd mergeR. Bioinformatics 30(5):614-620

DOI 10.1093/bioinformatics/btt593. 